\title{
ПЕРСПЕКТИВЫ ПРИМЕНЕНИЯ ПАТЕНТНОЙ СИСТЕМЫ НАЛОГООБЛОЖЕНИЯ ИНДИВИДУАЛЬНЫМИ ПРЕДПРИНИМАТЕЛЯМИ
}

\author{
(c) 2019 Баснукаев Муса Шамсудинович \\ кандидат экономических наук, доцент, \\ Чеченский государственный университет, Чеченская Республика, Грозный \\ (c) 2019 Баташев Руслан Вахаевич \\ старший преподаватель \\ Чеченский государственный университет, Чеченская Республика, Грозный \\ E-mail: Sandaho_89@mail.ru \\ (c) 2019 Эльжуркаев Ислам Янарсович \\ старший преподаватель \\ Чеченский государственный университет, Чеченская Республика, Грозный
}

В настоящее время упрощенные системы налогообложения для субъектов малого и среднего бизнеса стали неотъемлемым элементом налоговой системы Российской Федерации и заняли свое законное место в ряду инструментов и механизмов государственного регулирования экономики. В посткризисный период в условиях существования восстановительной экономики патентная система налогообложения - мера налоговой политики государства, направленная на облегчение администрирования, снижение административных издержек и сокращение доли теневой экономики.

Ключевые слова: предпринимательство, налоговая политика, специальные режимы, теневая экономика, патентная система налогообложения, администрирование, совершенствование.

Совершенствование отечественного законодательства в сфере налогового регулирования предпринимательской деятельности посредством специальных налоговых режимов осуществляется непрерывно. Примером тому является введенный с января 2019 года новый специальный налоговый режим - система налогообложения в виде налога на профессиональный доход. Он нацелен на обеспечение благоприятных условий деятельности малого бизнеса в России. Предполагается, что он будет проходить апробацию в пилотных субъектах Российской Федерации (Москва, Республика Татарстан, Калужская область, Московская область).

Необходимость разработки взвешенной налоговой политики регулирования налогообложения малого предпринимательства в России обосновывается: (1) тем, что многие виды деятельности, осуществляемые субъектами малого бизнеса, обеспечивают в стране не только продовольственную безопасность, но и положительно влияют на безработицу. Кроме того, услуги, оказываемые малым бизнесом, наиболее приближены к потребительским группам населения, а во многих случаях, они (товары, работы, услуги) имеют ярко выраженное социальное значение.
Поэтому любые изменения в налоговом законодательстве могут в краткосрочном периоде негативно повлиять на мобильность оказания услуг предпринимателями наиболее нуждающимся социальным группам населения; (2) индивидуальное предпринимательство, включающее в себя стартапы и малые технологические предприятия, должно стать одним из драйверов развития новой экономики РФ.

По данным органов государственной статистики за последние несколько лет наиболее актуальными и востребованными (в т.ч. по объему выручки) потребителями видами деятельности, оказываемых ИП являлись: сельское хозяйство; производство пищевых продуктов; торговля оптовая и розничная; производство одежды; производство готовых металлических изделий; строительство; водоснабжение, водоотведение; общественное питание; операции с недвижимостью; научные исследования и разработки; деятельность в области здравоохранения и социальных услуг; образование.

Развитие индивидуального предпринимательства в России за последние годы характеризуется следующим. Официальная статистика 2015-2018 гг. свидетельствует о небольших пози- 
тивных изменениях, связанных с увеличением общего количества субъектов малого и среднего (включая микропредприятия) предпринимательства (ИП) (рис. 1), и объемов инвестиций в основной капитал малых и микропредприятий.

Данные рис. 1 свидетельствуют о том, что развитие малого и среднего предпринимательства в Российской Федерации не идет ускоренными темпами. За период 2015-2018 гг. темпы роста количества индивидуальных предпринимателей, занятых в сфере малого и среднего бизнеса, в России составили всего лишь $112 \%$.

О примитивности развития структуры индивидуального предпринимательства в России свидетельствует разнонаправленная динамика роста количества ИП, относимых к различным категориям (рис. 2).

Так, несмотря на то, что за рассматриваемый период наблюдается рост общего количества ИП и числа занятых в сфере малого предпринимательства, официальная статистика свидетельствует о следующем [5]:

во-первых, реальный рост произошел за счет ИП, относящихся к микропредприятиям. По сравнению с 2016 годом абсолютный рост ИП в категории микропредприятий составил 278 тыс. ед., или на 8,5\%;

во-вторых, в целом по России наблюдается уверенная тенденция снижения количества индивидуальных предпринимателей, относящихся к среднему бизнесу. А в отдельных регионах РФ (Чеченская Республика, Карачаево-Черкесская

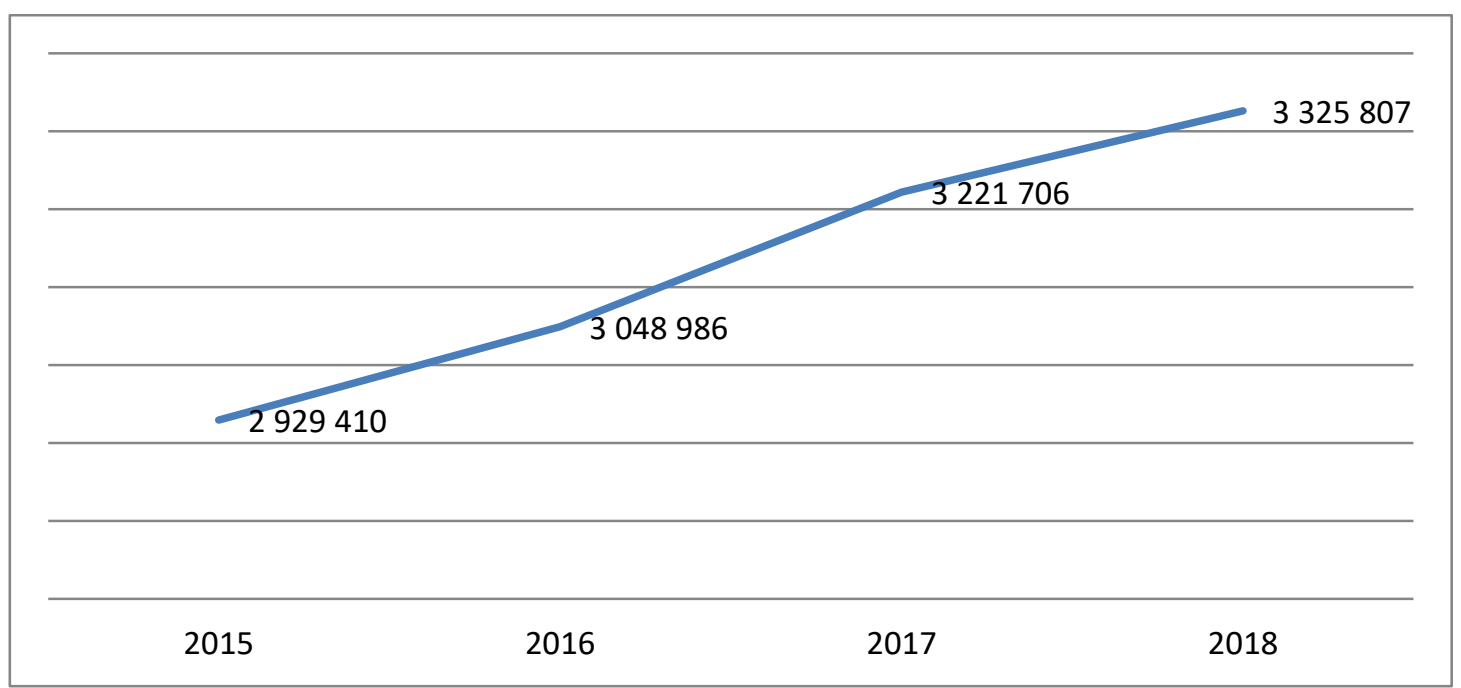

Рисунок 1. Динамика количества ИП, занятых в сфере малого и среднего бизнеса (2015-2018 гг.) Источник: составлено по данным ФНС России: https://rmsp.nalog.ru/statistics.html

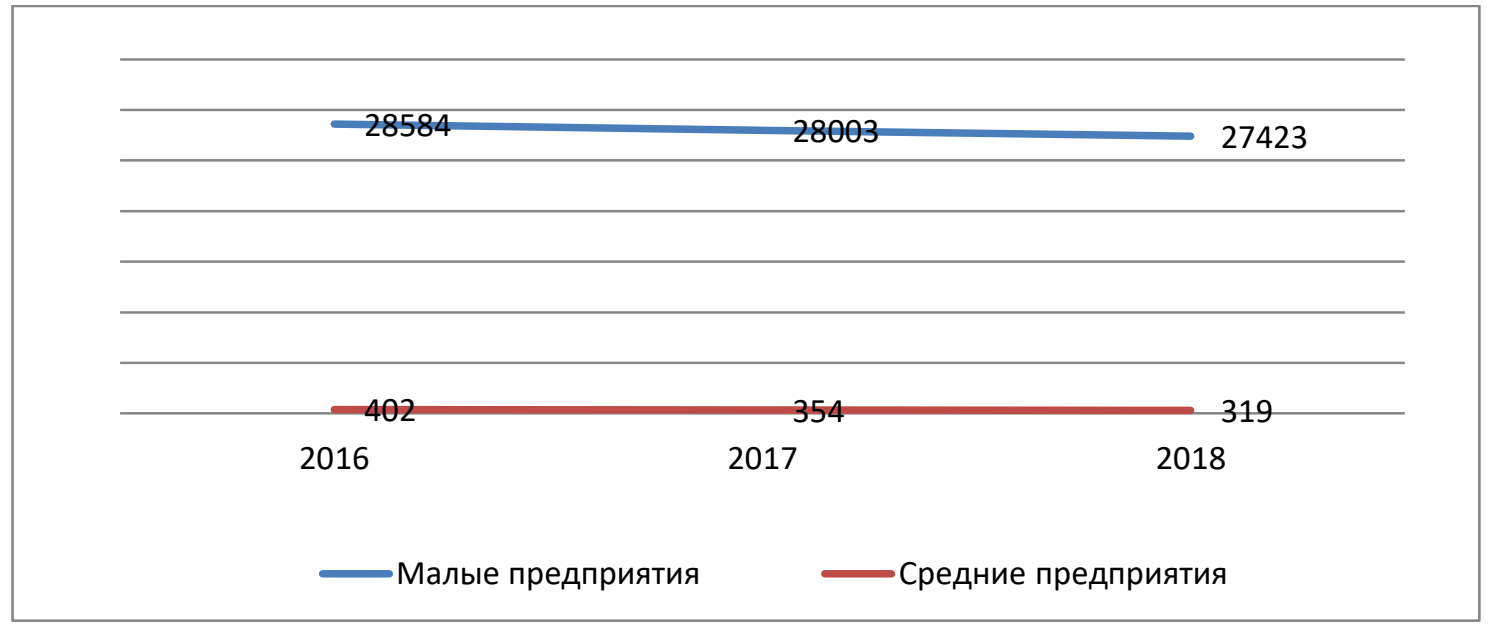

Рисунок 2. Динамика количества ИП, относящихся к среднему и малому бизнесу (2016-2018 гг.) Источник: составлено по данным ФНС России: https://rmsp.nalog.ru/statistics.html 
Республика, Республика Крым и др.) ИП в сфере среднего бизнеса вообще отсутствуют. Единственный федеральный округ, в субъектах которого ИП заняты в сфере среднего бизнеса,Центральный ФО;

в-третьих, количество ИП, относящихся к малому бизнесу, за последние три года снизилось на 1161 ед., достигнув значение 27423 ед. Северо-Кавказский ФО резко выделяется на фоне остальных ФО по минимальному количеству ИП в сфере малого бизнеса - 818 ед. по состоянию на 01.01.2018 г.

Если опираться на официальные данные ФНС России, содержащихся в Едином государственном реестре малого и среднего предпринимательства, то можно заметить один примечательный факт: нет ни одной записи об ИП, имеющих статус «вновь созданных» в сфере малого и среднего предпринимательства за рассматриваемый период. По состоянию на 01.01.2018 г. на долю микропредприятий приходится 99\% всех индивидуальных предпринимателей, занятых в сфере малого и среднего бизнеса. Между тем, малое и среднее предпринимательство - это именно те категории индивидуальных предпринимателей, которые в основном и создают добавленную стоимость в экономике.

Такими темпами экономика России может лишиться важнейших субъектов предпринимательства из-за подрыва устойчивой финансовой и нормативно-правовой среды их деятельности. Малое и среднее предпринимательство начало испытывать на себе существенные негативные отклики от принимаемых законодательных инициатив еще в 2013 году, кода произошло повышение соцвзносов. По данным ФНС России число ИП сократилось в 2013 году с 4 млн. до 3,4 млн. в 2014 году.

В условиях существования и развития современной экономики России главный аргумент в пользу необходимости непрерывного анализа практики налогообложения индивидуального предпринимательства и поиска дальнейших путей его совершенствования заключается в понимании того, что оно представляет собой динамичный и гибкий сектор экономики, чутко реагирующий на изменения рынка рабочей силы и способный смягчить удары кризиса.

Отечественные экономисты и практики все чаще отмечают, что основными причинами, сдерживающими стремительное развитие малого предпринимательства в России, являются: экономическая неопределенность, растущие издержки, снижение спроса и уровень налогообложения.

В частности, в докладе, представленном уполномоченным при президенте России по правам предпринимателей Б.Ю. Титовым [4], уровень налогообложения также позиционируется как один из основных негативных факторов, тормозящих развитие малого и среднего предпринимательства в России. Исходя из этого, в докладе ставится под сомнение адекватность российской налоговой политики в отношении предпринимательства, характеризуя ее как примитивный инструмент изъятия финансовых средств из частного сектора. Следуя данной логике, можно заключить:

1. налоговая политика для малого и среднего предпринимательства в России не выполняет одну из важных налоговых функций - стимулирующую;

2. современная государственная налоговая политика стимулирует субъектов малого и среднего предпринимательства к дроблению и выдавливанию в теневой сектор.

3. налоговая система РФ перегружена различными системами налогообложения, ориентированными на малое и среднее предпринимательство, что часто приводит к трудностям в выборе режимов налогообложения (особенно для непросвещённого в вопросах налогообложения ИП) и возникновению налоговых споров, и необходимости обращаться к консалтинговым услугам.

4. при совершении возможных налоговых маневров для ИП более предпочтительным является снижение тарифов страховых взносов.

О необходимости активного вмешательства, в том числе, посредством механизмов налогового регулирования в развитие малого и среднего предпринимательства в России было отмечено Президентом РФ. В связи с чем, в мае 2018 года Указом Президента Российской Федерации В.В. Путина был утвержден Национальный проект «Малое и среднее предпринимательство и поддержка индивидуальной предпринимательской инициативы», рассчитанный до 2024 года.

В качестве ключевых показателей развитости предпринимательского сектора традиционно выделяют: (1) число занятых в сфере малого и среднего предпринимательства; (2) доля малого и среднего предпринимательства в ВВП. 
На достижение указанных ключевых показателей и рассчитан принятый Национальный проект. Так, поэтапное увеличение доли малого и среднего предпринимательства в ВВП согласно проекту, должно составить до 32,5\% к концу 2024 г. При этом в базисном году доля малого и среднего предпринимательства в ВВП страны составляла 22,3\% (рис. 3).

На фоне принимаемых законодательных инициатив, направленных на поддержку МСП, продолжает снижаться общее количество ИП и их работников, занятых в указанной сфере. (рис. 4). Поэтому Национальным проектом предусмо- трены меры по увеличению численности занятых в сфере малого и среднего предпринимательства, включая ИП, до 25 млн. чел. к концу 2024 г., а стимулирование развития индивидуального предпринимательства позволит внести существенный вклад в достижении указанной цели.

Несмотря на многократные заявления отечественных экономистов-исследователей и налоговых практиков, Национальный проект не предусматривает как-либо радикальных мер по упрощению налоговой среды для малого и среднего предпринимательства. Предусмотрено

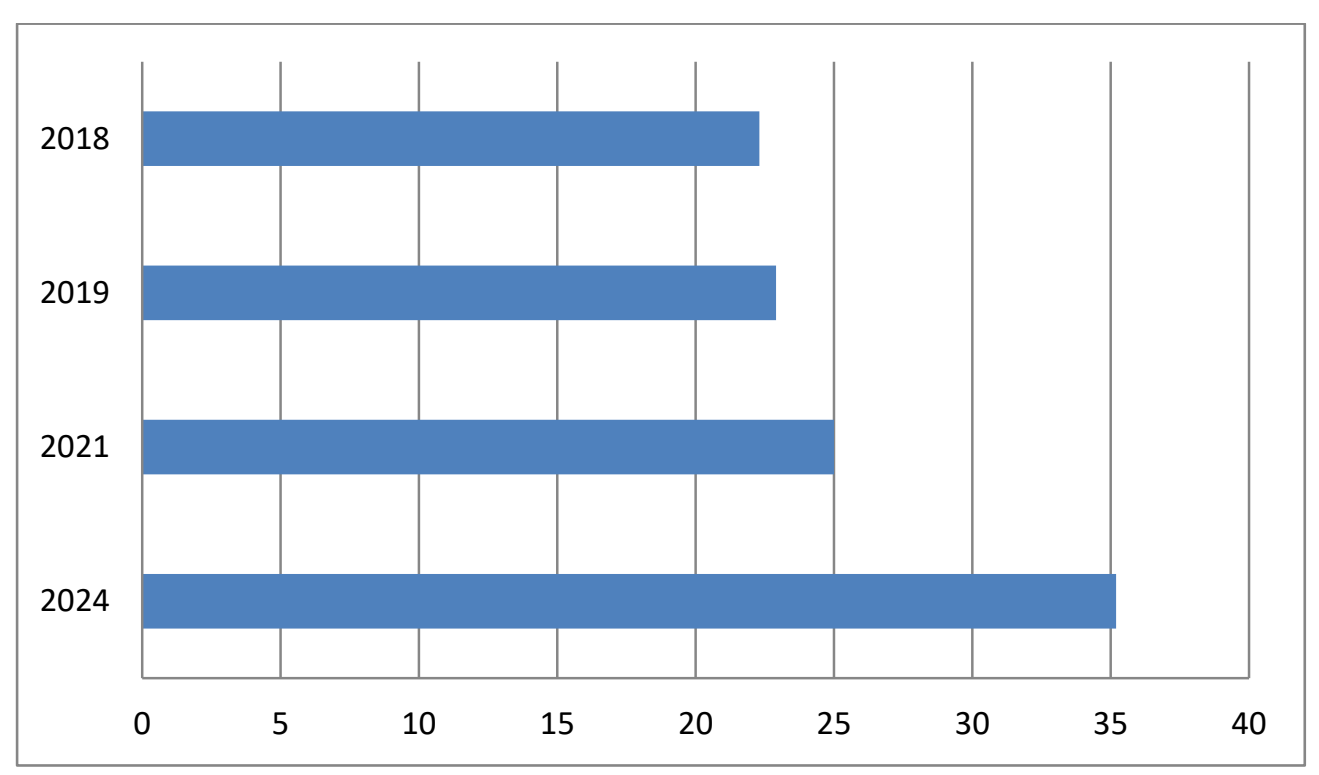

Рисунок 3. Увеличение доли малого и среднего предпринимательства в ВВП (\%) Источник: составлено по government.ru / projects / selection/738/35563/

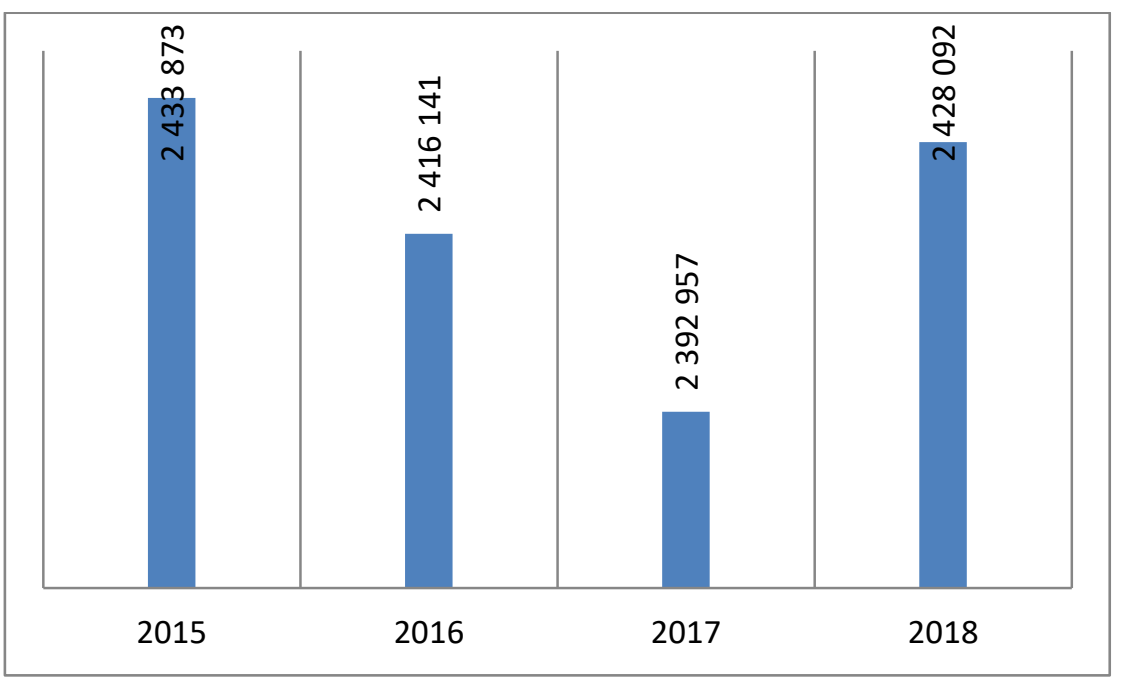

Рисунок 4. Количество ИП и их работников, занятых в сфере МСП Источник: составлено по данным ФНС России: https://rmsp.nalog.ru/statistics.html 
лишь поэтапное увеличение количества налогоплательщиков, применяющих ККТ и выбравших в качестве объекта «доход», освобожденных от предоставления налоговой отчетности по УСН (1,2 млн. до 2024 г.).

Вызывает сомнения и отнесение НПД к мерам, направленным на обеспечение благоприятных условий осуществления деятельности самозанятыми гражданами. Скорее, введение нового режима для самозанятых отвечает статистическим интересам, связанным с увеличением числа занятых в предпринимательском секторе, в первую очередь, за счет легализации их деятельности, а не за счет привлечения в данную сферу дополнительного количества граждан.

Обобщая отмеченные выше тенденции в развитии малого и среднего индивидуального предпринимательства в России, приходится констатировать, что применяемые на протяжении последних лет в рамках налоговой политики инструменты налогового стимулирования (спецрежимы) индивидуального предпринимательства имеют неоднозначный и противоречивый характер, о чем свидетельствуют такие показатели, как: общее количество ИП; численность занятых в сфере МСП; доля МСП в ВВП страны.

Одним из ярких представителей группы специальных налоговых режимов, предусмотренных для ИП, является, на наш взгляд, патентная система налогообложения. В налоговое законодательство РФ ПСН была введена с 2013 г. Федеральным законом от 26.06.2012 г. № 94-Ф3, по своей сущности заменив упрощенную систему налогообложения на основе патента, допустимую к применению индивидуальными предпринимателями [10].

ПСН направлена на обеспечение благоприятных условий деятельности малого бизнеса. А уровень развития малого бизнеса, как известно, признан одним из важнейших показателей состояния государственной экономики и учитывается при оценке уровня экономической безопасности [5].

Суть данного льготного режима налогообложения состоит в получении специального документа - патента, дающий право на осуществление определенного вида предпринимательской деятельности по перечню, определенным НКРФ.

Подчеркивая отсутствие каких-либо сложных процедур учета и отчетности, некоторые экономисты отмечают, что патентная система налогообложения в какой-то мере не является полноценной системой налогообложения. В виду своей простоты, «... для предпринимателей ПСН является действенной мерой налогового стимулирования, позволяющей осуществлять финансово-хозяйственную деятельность в реальном секторе экономики» [2]. Кроме того, в академической литературе можно встретить мнение, согласно которому патентная система налогообложения является инструментом налоговой политики, позволяющим решать вопросы уменьшения теневой экономики деятельности субъектов предпринимательства, деятельность которых наименее заметна для налоговых органов.

В исследовании Калиты Е.В. справедливо отмечается, что для экономики любой страны присущи виды предпринимательской деятельности, которые в силу специфики их осуществления и используемых систем расчетов в принципе сложно контролируемы налоговыми органами, а ряд видов деятельности- в принципе неконтролируемый [7]. Такой вывод, считает автор, является весомым аргументом для обоснования введения в налоговую систему государства презумптивного налогообложения, так как его конструкция представляется наиболее эффективным инструментом налоговой политики, позволяющим повышать эффективность контрольно-надзорной функции государственных органов при решении вопросов налогового регулирования указанных выше проблемных видов предпринимательской деятельности субъектов малого бизнеса.

Обосновывая важную роль патентной системы налогообложения для малого предпринимательства, выделяют следующие цели ее введения: [1]

- стимулирование экономического и социального потенциала предпринимательства;

- увеличение поступлений в бюджетную систему Российской Федерации путем выведения из неформального сектора экономики лиц, осуществляющих деятельность без регистрации в качестве индивидуальных предпринимателей;

- упрощение системы налогового администрирования, налогового учета и отчетности.

С момента введения в действие ПСН активно набирает популярность среди ИП, о чем свидетельствуют данные ФНС о растущем количестве ИП, применяющих ПНС, объеме налоговых поступлений и выданных патентов (табл. 1). Так, 
Таблица 1. Поступление платежей по налогам на совокупный доход за 2013-2018 гг.

\begin{tabular}{|l|c|c|c|c|c|c|}
\hline & 2013 г & 2014 г & 2015 г & 2016 г & 2017 г & 2018 г \\
\hline УСН (млн.) & 205,8 & 229,3 & 254,2 & 287,0 & 345,2 & 422,2 \\
\hline ЕНВД(млн.) & 72,6 & 76,6 & 78,5 & 74,3 & 70,6 & 64,5 \\
\hline ПСН (млн.) & 1,9 & 3,5 & 5,3 & 7,6 & 11,2 & 12,5 \\
\hline $\begin{array}{l}\text { количество выданных } \\
\text { патентов (единиц) }\end{array}$ & 88688 & 122098 & 24135 & 321606 & 383256 & 439088 \\
\hline $\begin{array}{l}\text { количество ИП, } \\
\text { применяющих ПСН (чел) }\end{array}$ & - & 99037 & 182198 & 243671 & 287766 & 325630 \\
\hline
\end{tabular}

темп роста налоговых поступлений по ПСН за последние пять лет составляет в среднем 47\% в год. Это в полтора раза больше аналогичного показателя по УСН и ЕНВД вместе взятых (118\%). Рост количества ИП, применяющих ПСН, за последние 5 лет в среднем составляет 24\% в год. Количество выданных патентов за тот же период растет с темпом 33\% в год.

Обобщая изложенное выше, можно констатировать, что ПСН в большей степени отвечает фискальным и регулирующим интересам государства. Кроме этого, ПСН является более простой и удобной в применении для налогоплательщиков. Однако здесь есть свои подводные камни.

Сложившаяся практика администрирования ПСН показывает, что многие налогоплательщики воспринимают ее с точки зрения «заплатил налог наперед и думать ни о чем не нужно, бухгалтер не нужен, отчетность не нужна». На самом деле, как показывает налоговая статистика, очень много налоговых проверок с доначислением огромных налогов происходит именно по патентной системе налогообложения. Поэтому применение ПСН предполагает наличие у налогоплательщиков знания нормативно-правовой базы и арбитражной практики ее применения в целях минимизировать риски доначислений со стороны налоговых органов.

Основная часть налоговых споров по вопросам применения ПСН возникает по следующим направлениям.

1. ОКВЭД. При регистрации бизнеса ИП обязательным требованием является определение конкретного вида предпринимательской деятельности, то есть должен быть определен ОКВЭД, внесенный в ЕГРИП. При отсутствии необходимого кода возможен налоговый спор изза неправомерности применения ПСН. Кроме того, налоговая может квалифицировать доход как личный и обложить по ставке $13 \%$.

2. Территория действия. Согласно гл. 26.5
НКРФ патент приобретается для осуществления предпринимательской деятельности на конкретной территории. Субъект РФ самостоятельно принимает решение о введении в действие на своей территории ПСН и устанавливает виды деятельности, в отношении которых она применяется. Данные положения необходимо учитывать при изменении географии осуществления предпринимательской деятельности. К примеру, если ИП приобрел патент на территории Чеченской Республики, а по факту уезжает работать в соседний регион, то в данном случае необходимо приобрести новый патент на территории соответствующего субъекта, где он и должен быть зарегистрирован.

3. Адрес оказания услуг. Часто на практике возникают вопросы, связанные с тем, кому ИП могут оказывать услуги: юридическим лицам или физическим лицам. Распространено ошибочное мнение, что услуги могут оказываться только физическим лицам. Однако НКРФ здесь не предусмотрено никаких ограничений. Это подтверждается и позицией Минфина.

4. Ограничения применения ПСН. Налоговым законодательством предусмотрено ограничение по объему доходов - 60 млн. руб. в год. На практике споры возникают при применении ИП нескольких режимов налогообложения (например, УСН и ПСН). В этом случае суммарные обороты по обеим системам налогообложения не должны превышать 60 млн. руб. в год.

Второй вид ограничения по применению ПСН - по численности работников. По НКРФ количество сотрудников не должно превышать 15 человек в год.

На практике налогоплательщики в целях налоговой оптимизации часто прибегают к «замене отношений», то есть трудовые отношения с физическими лицами заменяются на гражданско-правовые. Однако гражданскоправовые договоры входят в общее количество работников предприятия. 
5. KKT. Общераспространённой ошибкой является то, что применение ПСН не требует использование ККТ. При этом применение ККТ на ПСН зависит от конкретного вида предпринимательской деятельности, так как один патент может быть полностью освобожден от ККТ, другой - на определенное время.

6. Субподряд. Суть налоговых споров здесь заключается в том, могут ли налогоплательщики применять субподряд на оказываемые услуги. Позиция налоговиков и Минфина в данном вопросе однозначна: так как ПСН применяется самим налогоплательщиком, то применение субподряда не допускается.

В целом перечисленные проблемы ПСН на практике не создают каких-либо серьезных препятствий в ее применении. Они решаемы на стадии информационно-разъяснительной работы с налогоплательщиками без изменений законодательного характера.

Дальнейшее развитие налоговой политики в отношении ИП видится в унификации систем налогообложения для малого и среднего предпринимательства. Этим целям может отвечать дальнейшее развитие и внедрение ПСН, как специального режима, который могли бы применять не только микропредприятия, но и ИП, относящиеся к малому и среднему бизнесу.

На наш взгляд, необходимо упрощение Налогового кодекса и отмена многообразия налоговых льгот. Неравные конкурентные условия и являются одной из причин высокой смертности среднего бизнеса, вынужденного прибегать к дроблению. Важность среднего бизнеса заключается в том, что «... среди них много ресурсных и снабжающих предприятий, организаций с госучастием и филиалов западных фирм» [8].

Налоговую систему России необходимо перестроить так, чтобы были равные условия для всех субъектов индивидуального предпринимательства. Это возможно при условии, что большее количество ИП, относящихся к различным категория, получат одинаковые возможности по применению ПСН.

Активное внедрение вменного налогообложения в виде ПСН будет способствовать:
- воспрепятствованию уходу от уплаты налогов в сферах предпринимательства, где система налогового администрирования относительно слаба;

- снижению административной нагрузки в части осуществления проверок со стороны налоговых органов. В целях поддержания налоговой дисциплины целесообразным будет проведение налоговых проверок, носящих резонансный эффект для налогоплательщиков.

- снижению теневого сектора за счет возвращения бизнеса в налоговое поле. В этом случае важное значение может иметь мониторинг предприятий, чтобы они оставались в налоговом поле.

Основной риск расширения сфер применения ПСН - установление излишне высоких размеров потенциального дохода, что может привести к коррупции и «угнетению» налогоплательщиков, или в условиях слишком низких административных расходов и расходов на соблюдение требований налогового законодательства оно может по сути стать освобождением от налогов [9].

Для снижения указанного риска, внедрение ПСН должно сопровождаться усилением научно-методологической платформы в регионах в целях обеспечения объективной и соответствующей рыночным условиям работы органов власти по установлению размеров потенциально возможных к получению доходов налогоплательщиками.

Конечным результатом предлагаемых решений в области налогообложения индивидуальных предпринимателей станет создание оптимальных конкурентных условий для всех налогоплательщиков, что будет способствовать снижению неформального сектора ИП и в будущем росту налоговых поступлений в бюджет.

Предлагаемые преобразования налоговой системы РФ требуют дальнейшего научного изыскания и осмысления для установления потенциальных противоречий и практических недостатков повсеместного внедрения такого презумптивного налогообложения ИП как патентная система налогообложения.

\section{Библиографический список}

1. Абдулманапов П.Г. Перспективы развития патентной системы налогообложения в республике Дагестан // вопросы структуризации экономики. 2018. № 3. С. 32-33;

2. Ахмадеев Р.Г., Быканова О.А., Агапова А.А. Применение патентной системы налогообложения: фактор стабильности экономики // Азимут научных исследований: экономика и управление. 2018. Т.7. № 1 (22); 
3. Баташев Р.В., Эльжуркаев И.Я. Подходы к оценке эффективности налогового контроля на региональном уровне // Вестник Евразийской науки, 2018 № 3, https:/esj.today/PDF/59ECVN318.pdf (доступ свободный);

4. Титов Б.Ю. Сектор малого и среднего предпринимательства: Россия и Мир. http: // stolypin.institute / wpcontent /uploads /2018/07/ issledovanie-ier-msp-27.07.18;

5. Бобошко Н.M., Водянюк Е. В. Специальные налоговые режимы: сущность и значение в условиях обеспечения экономической безопасности бизнеса // Инновационное развитие экономики. 2018. № 4 (46). С. 305;

6. Единый реестр малого и среднего предпринимательства. Режим доступа: https://rmsp.nalog.ru/statistics. html

7. Калита Е.В. Патентная система налогообложения в Российской Федерации. 2010. Казань. 08.00.10

8. Налоговая политика и практика. 2019. № 1. С. 21

9. Перспективы налоговой политики. Существует ли «идеальная налоговая система» для России? / М.В. Алексеев, С. Г. Белев, В.В. Громов, А. Н. Д ерюгин, С. М. Дробышевский, А. С. Каукин, А.Ю. Кнобель, А. В. Корытин, Е.А. Леонов, Т.А. Малинина, Н.С. Милоголов, С.Г. Синельников-Мурылев.- М.: Издательский дом «Дело» РАНХиГС, 2019.- 126 с. - (Научные доклады: налоги).

10. Некрасова Т.Г. Ключевые недостатки патентной системы налогообложения // Экономика знаний: теория и практика. 2018. № 3 (7). С. 57.

11. Шаляева О.С. Налогообложение на основе патента: создание условий для заинтересованности предпринимателей в применение патентной системы // Налоги и налогообложение. 2016. № 1. С. 60-63. 